\title{
Juicios de residencia en el gobierno provincial de Maracaibo, 1765-1810*
}

\author{
Ligia Berbesí de Salazar \\ y Belin Vázquez de Ferrer
}

Facultad de Humanidades y Educación

Universidad del Zulia. Maracaibo, Venezuela

\begin{abstract}
Se estudia el juicio de residencia en la dinámica social y política de Maracaibo como capital provincial en el contexto de las relaciones de obediencia, dependencia y subordinación a la imagen sacralizada del rey y a los cuerpos sociales, comunidades y grupos a los cuales pertenece el residenciado. Se consideran la autoridad y el poder en el marco de normas, códigos y valores propios de la sociabilidad tradicional del Antiguo Régimen, así como la diversidad de vínculos que relacionaban e integraban jerárquicamente al colectivo, para explicar la complejidad del funcionamiento y socialización del poder local en el ejercicio del gobierno provincial de Maracaibo durante los años 1765 a 1810.
\end{abstract}

Este trabajo pretende analizar los juicios de residencia en el contexto socio-simbólico que explica el funcionamiento del poder en el gobierno provincial durante el régimen borbónico. Desde esta perspectiva, se estudia la aplicación de este procedimiento de control judicial rutinario animado por la normativa legal, para los gobernadores de la Provincia de Maracaibo entre 1765 y 1810 . Nuestro interés no se centra en determinar los beneficios o la ineficacia de la política monárquica, como tampoco en establecer opinión sobre su aplicación o los resultados. En todo caso, se analiza el juicio de residencia desde las redes de relaciones de obediencia, dependencia y subordinación a la imagen sacralizada del rey y a los cuerpos sociales, comunidades y grupos a los cuales pertenecen los residenciados. Se trata de explicar las denominadas residencias en la dialéctica del poder del reino - dividido en Cabildos y Gobernaciones- y el poder del rey.

En esta sociabilidad de tipo tradicional, la lógica del funcionamiento social del poder se corresponde con el espacio socio-simbólico de relaciones colectivas o comunitarias, en las cuales se mezclaban lo público y lo privado, lo político y lo social y, por tanto, el Estado y la socie-

* El trabajo es un avance del proyecto de investigación "Vínculos, símbolos y poder en el gobierno provincial de Maracaibo. 1787-1812", inscrito en el programa de investigación "Familia, cultura de elites y poder en Maracaibo. Siglos XVIII-XX", financiado por el Consejo de Desarrollo Científico y Humanístico de La Universidad del Zulia. 
dad. ${ }^{1}$ Según lo establecían las normas y los códigos de moral cristiana, la pertenencia a estas corporaciones colectivas y la concurrencia de poderes, demuestran que la autoridad y el poder en la vida del reino eran ejercidos por los grupos elitistas en el interior de las comunidades, con sus naturales relaciones de dependencia. Asimismo, de manera real y simbólica, funcionaban reglas de sometimiento, subordinación y dependencia a la autoridad de los cuerpos o comunidades a las que se pertenecía; campo social que estaba surcado por los actores individuales y colectivos quienes, mediante sus vínculos personales, actuaban como agentes directos del cambio social y político con rivalidades y alianzas. ${ }^{2}$

Este análisis relacional permite explicar las separaciones, diferencias o distancias sociales determinadas por la pertenencia a grupos diversos y a las diferencias en el interior de ellos, de acuerdo a las normas, atribuciones y posiciones de sus miembros respecto a las relaciones de dependencia. ${ }^{3}$ Desde estas diferentes y diferenciadas visiones del mundo social, el poder se entiende como práctica y representación, pues transita con el mundo cultural y en la dirección establecida por sus actores significativos.

Es el caso que en la América hispana las fidelidades, lealtades y solidaridades, estuvieron originadas por estas identidades socio-culturales compartidas entre iguales que se comunicaban en redes de sociabilidad. Esto explica que en las localidades y regiones, las alianzas fuesen decisivas para los acuerdos políticos en los órganos de gobierno, como era el caso de los Cabildos.

Por otro lado, el vacío de poder del gobierno monárquico declarado con las medidas comerciales y político-administrativas para reponerlo, devela que el poder del reino se había afianzado con los grupos que dominaban el escenario social, económico y político a finales del siglo XVIII, verificado por las parentelas surgidas del arribo de inmigrantes, estimulados por el despegue de la actividad mercantil quienes, de manera directa o indirecta, tuvieron el control de los órganos de gobierno civil, militar y eclesiástico, tal como ha quedado demostrado con nuestras investigaciones. ${ }^{4}$

1 Sobre este tema se recomienda consultar Soriano de Garcia-Pelayo, G.: "Aproximación histórica a lo público y lo privado, a otras nociones afines y a sus mutuas relaciones desde una perspectiva pluridimensional", en Soriano de Garcia-Pelayo, G. y Njaim, H. (edits.):Lo público y lo privado. Redefinición de los ámbitos del Estado y de la sociedad, Caracas, 1996, T. I, págs. 29-59.

2 Imizcoz Beunza, José M. ${ }^{a}$; Élites, poder y red social. Las élites del País Vasco y Navarra en la Edad Moderna (Estado de la cuestión y perspectivas), Bilbao, 1966, págs. 14-19.

3 Ibídem.

4 Vázquez de Ferrer, B., G. Rijos y N. Ferrer: "Grupos de poder y pautas de comportamiento social en las familias maracaiberas del antiguo régimen", en Revista Mañongo, 9, 1997, págs. 67-98; Vázquez de Ferrer, B., L. Berbesí y N. Varela: "La familia Baralt-Sánchez como modelo de la elite 
Dentro de esta dinámica social y política, los juicios de residencia o las residencias funcionaron como instrumentos de centralización políticoadministrativa y judicial, así como de dominación política por parte de la administración monárquica. Su objetivo fundamental consistía en el control y la intervención sobre los gobiernos y haciendas locales. En el marco del simbolismo político de la época, las residencias evidencian, por una parte, la autoridad y el poder tanto del rey como del reino y, por otra, la complejidad de los vínculos y relaciones establecidas en el interior de las localidades y sus capitales provinciales en el marco de normas, códigos y valores propios de la sociabilidad tradicional; además, constituían el instrumento idóneo para afianzar la justicia, fortalecer y legitimar la institución monárquica.

Hasta el presente, al menos en lo que conocemos, el tema no ha sido abordado desde la perspectiva planteada, en razón de lo cual el análisis se ha centrado en fuentes documentales localizadas en archivos españoles, colombianos y venezolanos. Si bien no se ha cumplido una revisión exhaustiva de las posibles fuentes, las utilizadas suponen un material suficiente para que los resultados obtenidos puedan ser matizados con otras investigaciones.

\section{Aproximación al balance historiográfico}

La producción historiográfica sobre la normativa que regula los juicios de residencia - al menos en sus obras más significativas - constituye una herramienta útil en la medida que aporta datos y referencias sobre su carácter jurídico-institucional. Estas fuentes han sido lo suficientemente explícitas, de ahí su valoración.

Desde nuestro punto de vista, la obra pionera referida a las modalidades del juicio de residencia es la de José Mariluz Urquijo. ${ }^{5}$ Su trabajo describe las disposiciones expedidas por la Corona, mediante las cuales virreyes, Audiencias y Cabildos procedían a legislar. Asimismo, ofrece aportes sobre los hitos que marcan su proceso en Indias. Según su criterio, la escasez de obras especializadas reduce al análisis a fuentes inéditas localizadas

maracaibera durante las últimas décadas borbónicas", en Boletín Americanista, 47, Barcelona, 1997; págs. 215-232; Vázquez de Ferrer, B.: "Matrimonio, estatuto social y poder en la familia maracaibera de fines del antiguo régimen”, en Revista Opción, 22, 1997, págs. 5-26.

5 Ensayo sobre los Juicios de Residencia Indianos, Sevilla, 1952. 
en archivos argentinos y españoles. Entre las obras consideradas como clásicas, destaca las de Castillo de Bovadilla, Villadiego, Hevia, Solórzano y Bolaños, quienes han estudiado los juicios de residencia peninsulares en el contexto de la legislación indiana, pero sin detallar las particularidades del mismo en territorios americanos. A esta producción de base añade los estudios sobre historia del derecho indiano que registran el conjunto de normas jurídicas exclusivas con carácter general o particular para las Indias Occidentales: instrucciones, ordenanzas, provisiones y reales cédulas conocidas como derecho indiano propiamente. Entre otros cita los trabajos de Muro Orejón, Ots Capdequí, Haring, Aguiar y Acuña y Aguirre. ${ }^{6}$ Son estudios esencialmente institucionales que constituyen una referencia obligatoria y su utilidad es incuestionable.

La producción historiográfica sobre las disposiciones jurídicas y los juicios de residencia en la Venezuela colonial, al menos la conocida hasta ahora, es muy escasa. No obstante, la existente es de un valor inexcusable, en unos casos, o, al menos de cita imprescindible en otros. ${ }^{7}$ Todos remiten a aspectos concretos y, por lo general, muy puntuales dentro del ordenamiento jurídico indiano. A partir de posturas propiamente institucionales, los estudios han centrado su atención en los funcionarios que ejercieron el gobierno en la provincia de Venezuela, viéndoles como individualidades descontextualizadas y en respuesta a la normativa sobre la que se asienta el gobierno monárquico.

6 Muro Orejón, Antonio: El nuevo código de las Leyes de Indias. Proyectos de recopilación legislativa posterior a 1680. Tesis doctoral, Madrid, 1929; Ots Capdequí: Historia del derecho español en América y del derecho indiano, Madrid, 1969; Haring, Clarence: "El Origen del gobierno Real en las Indias Españolas", en Boletín del Instituto de Investigaciones históricas de la Facultad de Filosofía y Letras, Buenos Aires, Año III, tomo 3, N. ${ }^{\circ}$ 24, abril-junio de 1925; Aguiar y Acuña, Rodrigo: Sumario de la Recopilación General de las leyes, Ordenanzas, Provisiones, Cédulas, Instrucciones y Cartas acordadas por los Reyes de Castilla, se han promulgado, expedido y despachado para las Indias desde el presente de 1628, México,1677; Aguirre, Severo: Prontuario alfabético y cronológico por orden de materias de las Instituciones, Ordenanzas, Reglamentos, Pragmáticas y demás Reales Resoluciones no recopiladas que han de observarse para la administración de justicia y gobierno de los pueblos del reino, Madrid, 1794.

7 Destacan los trabajos de Bello Lozano, Humberto: Historia de las Fuentes e Instituciones Jurídicas venezolanas, Caracas, 1966; Castillo Lara, Lucas: Cedularios de la Monarquía española relativos a la provincia de Venezuela.1529-1552, Caracas, 1959, 2 Ts.; Tosta, Virgilio: Dos Juicios de Residencia en la Ciudad de Barinas; Ponce, Marianela: El control de la gestión administrativa en el Juicio de Residencia al Gobernador Manuel González Torres de Navarra, Caracas, 1992, 3 Ts.; Ponce, Marianela, Diana Rengifo y Leticia Vaccari: Juicios de Residencia en la provincia de Venezuela. Los Welser; Caracas,1977; Ponce, Marianela, y Letizia Vaccari: Juicios de Residencia en la provincia de Venezuela.Juan Pérez de Tolosa y Juan de Villegas, Caracas,1980; Vaccari, Letizia: Juicio de Residencia en la provincia de Venezuela. Don Francisco Dávila Orejón Gastón (1663-1677),Caracas, 1983, 3 Ts.; Vaccari, Leticia: Sobre gobernadores y Residencias en la provincia de Venezuela (Siglos XVI, XVII, XVIII). Caracas, 1992. 
No cabe duda que esta historiografía está convenientemente valorada con sus limitaciones. De una parte, no permite arribar a conclusiones válidas para espacios y tiempos históricos más amplios que los estrictamente considerados. Por la otra, no logra explicar el juicio de residencia en el contexto de la diversidad de relaciones e interdependencias recíprocas, complejas y jerárquicas que sustentan el ejercicio y funcionamiento del poder; sin embargo, proporcionan datos sobre el ordenamiento jurídico.

A excepción de estos estudios, para el conjunto de las provincias venezolanas durante el gobierno monárquico, no se han realizado investigaciones con cierto rigor metodológico dedicadas a esta materia desde el enfoque aquí planteado. El problema que, en definitiva, se trata de plantear y, en lo posible, resolver es escudriñar sobre lo que este instrumento de control representó y significó dentro del sistema político y de la estructura de poder en Maracaibo entre 1765 y 1810 . Nuestro objetivo consiste en analizar los juicios de residencia a partir de las relaciones de dominación, de dependencia, de lealtad, de fidelidad y de subordinación que integraban a individuos y colectivos, en correspondencia con los códigos simbólicos que expresaban sus prácticas sociales.

\section{El juicio de residencia en el contexto hispano colonial}

En su sentido más general, los estudios que aluden al juicio de residencia parten por considerar la estructura esencial que mantuvo en España y con la cual se trasladó a América. En tal sentido, se remontan al código de Alfonso X, el Sabio, entre 1256 y 1263 conocido con el nombre de las Siete Partidas, al ordenamiento de Alcalá de Henares, fuente del derecho castellano promulgada en 1348, a las Cortes de Toledo de 1480 y a la Pragmática para corregidores y jueces de residencia publicada en Sevilla en $1500 .{ }^{8}$

Las particularidades que adquirió en la América hispana, al igual que toda la legislación indiana, figuran en la Recopilación de Leyes de Indias promulgadas por Carlos II en el año de 1680. Sin embargo, la especificidad americana impuso, en algunos casos de residencia, la necesidad de recurrir a las fuentes del derecho castellano con carácter supletorio. Es convenien-

8 La bibliografía sobre el origen y la normativa jurídica del juicio de residencia es abundante. Aquí se ha tomado como referencia la ofrecida por José M. ${ }^{\text {a }}$ Mariluz Urquijo en su obra citada Ensayos sobre los Juicios de Residencia... 
te señalar que como institución no fue privativo de Castilla; otros reinos, al considerarlo como instrumento ideal para el fortalecimiento de la monarquía, reglamentan y disponen del mismo según sus particularidades.

Con el ascenso de los Reyes Católicos al gobierno monárquico, la residencia adquirió el fortalecimiento necesario para instaurarse definitivamente como institución legalmente constituida. A partir de 1500 los lineamientos establecidos en la Nueva Recopilación de las Leyes de Castilla permitieron su traslado a América para el control efectivo de los funcionarios en los territorios ultramarinos. En opinión de Haring, ${ }^{9}$ la residencia en América se instauró en 1501, cuando se autorizó a Nicolás de Ovando tomar la residencia a Francisco de Bobadilla, procurador en estas tierras.

Dada la diversidad de situaciones que se presentaron en tierras americanas para su aplicación, la Corona se vio obligada a adecuar las disposiciones dándoles un carácter específico. Letizia Vaccari ${ }^{10}$ advierte que esta institución evolucionó en el Nuevo Mundo y adquirió características que permiten diferenciarla en el conjunto americano. En todo caso, puede decirse que fue más indiana que española. Aunque su origen y cometido fue convergente, no existió un patrón único en la forma de su desarrollo y de su práctica. No obstante, la realidad política, económica, social y geográfica de los territorios americanos, llevó a la Corona a ceder ante el imperativo de las circunstancias impuestas por dicha realidad. Era evidente que, a pesar de existir ya desde el siglo XVI una normativa respecto al control de los oficios y gobiernos, su aplicación fue muy desigual; en ello incidió desde la propia realidad americana, hasta los intereses particulares que se filtraban en las instituciones de poder local.

De este modo, se fueron delineando políticas atendiendo a circunstancias locales específicas, pues constituyó un reflejo fiel del proceso de adaptación y cambios a nuevas y diferenciadas realidades. ${ }^{11}$ La segunda mitad del siglo XVIII, bajo el amparo de nuevas leyes y de tendencias centralizadoras e impositivas por parte de los gobernantes ilustrados, se dio un vuelco a esta práctica, que si bien se proponía contribuir al buen gobierno y administración local, generó cierta complicidad en el disfrute colectivo de los recursos y bienes públicos.

En la dialéctica del poder del reino - dividido en Cabildos- poder del rey, los juicios de residencia fueron claves en el orden institucional de

9 Citado por Mariluz Urquijo, pág.12.

10 Vaccari: Sobre Gobernadores y Residencias..., pág. 39.

11 Ibídem, pág. 41. 
centralización político-administrativa y judicial y de dominación política, a la vez que contribuyeron al fortalecimiento del poder real en la medida que controlaban, entre otros aspectos, las finanzas locales. Lo anterior prueba que el aparato institucional del Estado absoluto descansó sobre los Cabildos, por ser instrumentos de administración y captación de recursos económicos. ${ }^{12}$

En la trama de las instituciones indianas, en opinión de Mariluz Urquijo, ${ }^{13}$ el juicio de residencia hacía posible el funcionamiento de los diversos organismos administrativos y judiciales, pues advertía al funcionario sobre la necesidad de ajustar sus actos, prácticas y comportamientos al ordenamiento jurídico vigente. En este sentido, se instituyó como discurso legitimador del poder público, a la vez que de los intereses individuales y públicos. Sin embargo, se duda de su efectividad, sobre todo en los funcionarios de alto rango: en algunos casos no concluían con sentencia; otros eran interminables en el tiempo y, otras veces, las influencias permitían su dispensa.

La dispensa o exención de la residencia, en el caso de algunos funcionarios, solicitada por él mismo o por los allegados a su entorno, provocó discusiones y encontradas decisiones judiciales. El problema se hizo muy evidente, sobre todo en el caso americano, durante la segunda mitad del siglo XVIII, a raíz del reformismo borbónico que facultaba a los funcionarios a exigir respeto a sus privilegios y recompensas a sus méritos. En adelante, virreyes, oidores, ministros de Audiencias, militares y gobernadores, entre otros funcionarios, se sintieron con derecho a exigir ante las autoridades respectivas la dispensa de su residencia.

Para la segunda mitad del siglo XVIII las dispensas se generalizaron y se convirtieron en práctica común. Por diferentes razones a buena parte de los funcionarios coloniales se les otorgó tal beneficio. La normativa legal establecía que la exención sólo procedía para la parte secreta; la pública debería darse, pues en ella los agraviados podían hacer valer sus derechos. ${ }^{14}$

12 La acción fiscalizadora de las finanzas municipales era ejercida por el Consejo de Castilla. Se trataba de una intervención ordinaria establecida directa y bilateralmente entre ambas instituciones del Estado. Al Consejo le correspondía el poder político-legal y al municipio la acción administrativa o ejecutiva. En todo caso, el Consejo de Castilla tomaba las decisiones sobre cualquier asunto relacionado con las finanzas municipales en general y de propios en particular. Por consiguiente, no existió en el ámbito local ninguna autonomía financiera, porque tampoco disfrutaron de autonomía política. Al respecto véase De Bernardo Ares, José: "La configuración del poder público en la Corona de Castilla a finales del siglo XVII", en Revista Tiempo y Espacio, N. ${ }^{\circ} 20$, Caracas, 1993, págs. 20-21.

13 Mariluz Urquijo: Ensayo sobre Juicios... págs. 4-5.

14 Ibídem, págs. 106-110. 
Sobre el momento preciso en que procedía el juicio de residencia se han suscitado polémicas. Para unos, debía realizarse al final del cumplimiento de sus funciones; para otros, en el ejercicio de su oficio o antes de haberse cumplido el tiempo previsto. Al respecto José Mariluz ${ }^{15}$ señala que el juicio podía abrirse en cualquier momento y tomarse en el sitio donde el funcionario cumplía su labor, por lo cual tenía que permanecer en el mismo durante el plazo fijado por la ley para su inicio, una vez concluidas sus funciones al servicio monárquico.

Todo juicio de residencia constaba de dos partes: una secreta, en la cual se investigaba la conducta del funcionario en forma sumarial; otra pública en la cual se recibían las quejas y denuncias de particulares, que se sentían ofendidos por el funcionario residenciado. En cualquiera de los casos, el juez de residencia recogía evidencias sobre todo de aquellos elementos que en conjunto representaban el funcionamiento administrativo de una localidad. La inspección implicaba, a su vez, la revisión de libros de Cabildo, protocolos, ordenanzas reales, expedientes sobre causas civiles y criminales, inspección de establecimientos municipales como la cárcel, carnicería, limpieza y construcción de calles, caminos y puentes, entre otros. Otro de los elementos a considerar eran las fianzas de residencia que, según disposiciones reales, debían presentar los funcionarios sujetos a la misma. La fianza aseguraba la efectiva aplicación de las sanciones impuestas, siempre a favor de los agraviados. El monto y las condiciones que regían su cumplimiento atendían a las particularidades locales. En la mayoría de los casos, los funcionarios aseguraban la fianza con algún miembro de la sociedad local que formaba parte del entorno del gobernador.

Dentro del simbolismo político de la época, además de recordarle a cada funcionario sobre la necesidad de ajustar todos sus actos, exhortaba a la población a pedir justicia por los agravios cometidos en su contra por cualquier funcionario en el ejercicio de su cargo. Para la Corona era fundamental el cumplimiento y aplicación efectiva de las disposiciones reales, y para ello sólo contaba con la capacidad, honestidad y ética de cada funcionario, reflejada en su nivel moral y político. ${ }^{16}$ Por lo tanto, simbólicamente constituía instrumento ideal para afianzar la justicia y fortalecer la monarquía.

Para el caso de la provincia de Maracaibo, esta institución se analiza como representación de la fidelidad política y la lealtad mutua en el marco 
del entramado social que articula cuerpos sociales, comunidades y grupos colectivamente vinculados por relaciones de diversa índole. Por tanto, su interpretación histórica debe enmarcarse en la "mentalidad política" de la época, de lo que representan y significan como parte del sistema político y de la estructura de poder.

\section{Los juicios de residencia en el gobierno provincial de Maracaibo. 1765-1810}

En su condición de ciudad-puerto y capital provincial, para las últimas décadas del siglo XVIII Maracaibo era el centro dinamizador de un mercado regional que concentraba las producciones cacaoteras de los valles cucuteños y tierras aledañas al Lago de Maracaibo. Como centro políticoadministrativo, también las lealtades, mediaciones y fidelidades mutuas explican el significado de las actuaciones y prácticas sociales que dinamizan el funcionamiento del poder durante el mandato de los gobernadores de Maracaibo en tiempos del régimen borbónico.

Los juicios de residencia, celebrados en la época aquí considerada, responden al entramado social que articulaba los diferentes cuerpos sociales, en el marco de unas pretensiones de poder institucionalizadas en la autoridad monárquica. Son varios los ejemplos de referencia documental que revelan lo sistemático de esta práctica y su revisión indica que la misma afectó muy poco la estructura del poder provincial. En este sentido, el entorno de los gobernadores y su gobierno lo integraban hacendados, comerciantes, propietarios y/o funcionarios, vecinos, hermanos, amigos, compadres y cuñados con prácticas que impregnaban la vida cotidiana local para el disfrute de los beneficios que el poder generaba.

Todo indica que las residencias ordenadas en la provincia de Maracaibo entre 1765 y 1810, son reveladoras de las relaciones entre el poder local y el monárquico y entre los cuerpos sociales locales vinculados al gobierno provincial. Desde esta perspectiva, la residencia y su exención pueden considerarse como parte del interés económico y político de quienes tenían acceso a diversas instancias de poder y como una manifestación más de poder. Ello explica la actitud asumida por los miembros del gobierno civil, militar y eclesiástico de Maracaibo, al solicitar su dispensa para la mayoría de los gobernadores que ejercieron el gobierno provincial durante estos años. 
El juicio ordenado a Alonso del Río, ${ }^{17}$ quien gobernó la provincia entre 1765 y 1775, fue uno de los más polémicos dada la opinión generalizada de la conducta "inhonesta" de dicho funcionario. Uno de los acusadores más fuertes fue el vicario juez eclesiástico de Maracaibo, quien en todo momento le acusa de "escandalosa y relajada vida" y se eleva su protesta directamente al virrey de Santa Fe, Pedro Messía de la Cerda. El obispo tomó declaración a quince testigos. Todos coincidían en lo perjudicial que resultaba a la vindicta pública, la situación de amancebamiento del gobernador con doña Bárbara Carrasquero, madre de su esposa. Además, se le acusaba de ser un funcionario despótico y ofuscado en sus pasiones, de haber abandonado la ciudad y de escandalosa conducta.

En iguales circunstancias, la residencia secreta sentenció 31 cargos concernientes a la violación de las disposiciones legales para el buen funcionamiento de la provincia, las buenas maneras y costumbres y, lo más grave, su escandalosa conducta. Entre los testigos acusadores figuraban varios vecinos de reconocida solvencia moral y económica, como don Francisco Vera, don Felipe Miguel de Inciarte, don Guillermo Roo, don Luis de Celis, don José Antonio Pulgar, don Cristóbal de Hoyo, don Juan Monzant y don José Miguel Puche.

Al gobernador se le impuso una multa de 82 pesos y 1027 salarios, en correspondencia con los 10 años, 3 meses y 20 días que se mantuvo en el ejercicio del cargo. ${ }^{18}$ En esta oportunidad el resultado de la pesquisa demuestra que los intereses de los vecinos se unen en defensa de su patrimonio local, de su solvencia moral, de ahí que la sentencia sea recibida con beneplácito por todos.

En el caso de los gobernadores Francisco de Santa Cruz (1775-1780) y Francisco de Arce (1782-1787), su testamentario y albacea don Bernardo de Lizaur, ante la imposibilidad de finalizar las testamentarias sin evacuar la residencia, solicitó la dispensa en consideración a que ambos funcionarios habían fallecido. La representación de Lizaur observaba haber depositado las fianzas correspondientes a los cargos que pudiesen resultar del proceso y pidió su indulto, pues su objetivo “... era averiguar la conducta y operaciones de los sindicados y si ya estos,...han fallecido la misma sería de muy poco fruto, acarreando mayores costos a sus bienes y perjuicios a sus herederos". ${ }^{19}$ Por real cédula en 1790 , fue indultado de la residencia

17 Archivo General de Indias (en adelante AGI), Caracas, 245.

18 Archivo Histórico Nacional de Madrid, (en adelante AHNM), Consejos, 20473.

19 AGI, Caracas, 14. 
secreta, más no la pública, dado el perjuicio ocasionado a terceros. También se ordenó suspender, hasta tanto se decidiera otra cosa, cualquier procedimiento contra los demás funcionarios de este gobierno.

En el juego de intereses colectivos entre quienes compartían el ejercicio del poder la dispensa de las residencias, generalizada desde mediados del siglo XVIII en el conjunto americano, revela las nuevas modalidades de las relaciones entre el soberano y sus súbditos. De esta manera, en el marco de la subordinación y dependencia a la imagen sacralizada del rey, la necesidad de control del poder de la monarquía debía responder a las aspiraciones de poder en los súbditos. Simbólicamente la identificación poder real / poder soberano era una representación de la lealtad y fidelidad política.

El juicio de residencia seguido a Joaquín Primo de Rivera, gobernador de la provincia de Maracaibo entre 1787 y 1794, al igual que los ordenados a otros funcionarios de este rango, descubre prácticas y comportamientos que explican las relaciones durante el mandato del gobierno provincial. Mediante real cédula fechada en San Lorenzo el 11 de octubre de 1792, se designó como juez residenciador a don Faustino de la Plaza, abogado de la Real Audiencia de Santo Domingo y del Ilustre Colegio de Caracas, teniente de gobernador y asesor general de la provincia de Barinas; en caso de ausencia, sería el licenciado don José Patiño y Sotomayor, teniente coronel del regimiento de infantería Fijo de Guatemala y, en ausencia de ambos, el licenciado Francisco Javier Manzanos, abogado de la Real Cancillería de Granada. A su vez, fue designado como escribano don Isidoro González de Acuña, fiscal de Real Hacienda: "todos sujetos de reconocida trayectoria y aptos para tan delicada misión".

Por real cédula se ordenaba que, junto al gobernador Primo de Rivera, debían rendir cuentas de su actuación el teniente de gobernador y auditor de guerra, tenientes de justicias mayores de las distintas jurisdicciones provinciales, corregidores de pueblos, regidores, alcaldes provinciales, ordinarios, de la Santa Hermandad, en fin a todos los que ejercieron funciones de gobierno durante este período. ${ }^{20}$ Señalaba que la residencia debía ajustarse por todas las vías y maneras a lo establecido legalmente, de manera que “...podáis, informéis y sepáis cómo y de qué manera han usado y ejercido sus oficios, han administrado justicia, derecho, preeminencia y patrimonio real, y en especial en lo tocante a los pecados públicos y cómo han guardado las leyes, cédulas y ordenanzas reales...". ${ }^{21}$

20 AHNM, Consejos, 20481, f. 2vto.

21 Ibídem. 
El procedimiento ordenado por el juez residenciador estableció las siguientes pautas para la rendición de cuentas:

- El escribano de Cabildo debería certificar con la presencia de los libros capitulares el día, mes y año en que tomó posesión de la gobernación de la provincia el brigadier Primo de Rivera, así como el día en que cesó en sus funciones. Asimismo, si en ese momento ya estaba posesionado del cargo su teniente y asesor general don Juan Esteban de Valderrama.

- Igualmente debería certificar que otros funcionarios cumplieron o estaban cumpliendo función alguna.

- Certificar si el gobernador era deudor de la Real Hacienda.

- Ordenar al escribano poner una certificación de todos los Cabildos ordinarios y extraordinarios celebrados durante dicho gobierno.

- Ordenar a los escribanos que le pasasen todos los registros, expedientes y causas actuadas en los juzgados ordinarios.

- Ordenar a los escribanos más antiguos que certificasen si el gobernador y sus funcionarios tenían fijado en tabla en la Real Audiencia, el real arancel de derechos.

- Ordenar suspender durante el término de la residencia al alcalde ordinario de primera elección. Igualmente al teniente de gobernador y asesor general don Juan Esteban de Valderrama. Sólo podían continuar en su cargo el auditor de guerra y el asesor general de la Intendencia.

- Ordenar examinar 18 testigos imparciales y mayores de edad.

Una vez evacuados los recaudos necesarios, el juez residenciador ordenó publicar solemnemente la residencia, tanto pública como secreta, fijando edictos en los lugares públicos acostumbrados. ${ }^{22} \mathrm{~A}$ partir de estas exigencias, bajo juramento los testigos elegidos debían responder el interrogatorio secreto formulado, que tenía como objetivo fundamental investigar de oficio la conducta del gobernador (ver apéndice).

Este interrogatorio de 41 preguntas, por lo general igual al resto de los ordenados en otras localidades en el período aquí considerado, introduce algunos matices locales que indican unas pautas de comportamiento asumidas colectivamente. En el marco de la política monárquica, se trata de determinar la aplicación y efectividad del conjunto de ordenanzas y dispo-

22 Archivo General de la Nación (Caracas), (en adelante AGN), Causas de residencia, T. LXXII, ff. 24-25vto. 
siciones reales que la legislación indiana dispuso para la administración de los territorios americanos.

Su contenido refleja los cargos y funciones de gobierno, así como el comportamiento de los vecinos. En este sentido, suministra información sobre diversos asuntos: costumbres, ejecución de obras, salud pública, ornato y aseo de la ciudad, Real Hacienda, asistencia social, recursos públicos, etc. Al manifestar la cotidianidad local, se describe un modo de actuar y una manera de relacionarse en el marco de la fidelidad y de la lealtad.

En la residencia secreta ordenada al gobernador Primo de Rivera se designaron diez y ocho testigos entre militares y comerciantes distinguidos, así como funcionarios que habían ocupado alguna plaza en el Cabildo; además, algunos vecinos carpinteros, herreros, sastres, entre otros. Los testigos "... imparciales honrados, de acreditada conducta y reputación, de buena familia y cristianos..." ${ }^{23}$ fueron don Sebastián Troconis, alcalde de la Real Aduana; don Guillermo De Roo, teniente de infantería; don Juan Monzant, vecino, labrador; don Pedro Fermín de Rivas, ayudante mayor del cuerpo veterano; don Francisco de Larrumbide, capitán de milicias, comerciante; don José Díaz Varela, vecino, comerciante; don Manuel Flores, vecino, comerciante; don Francisco de Iturbe, oficial de las reales cajas; don José Domingo Rus, abogado de la Real Audiencia; don Rafael María Zurbarán, oficial 2..$^{\circ}$ de la Real Contaduría; don Tomás de Quintana, teniente de milicias; don Domingo González, vecino, labrador; don José Ventura Socorro, vecino, maestro carpintero de blancos; don Ramón Govea, vecino, maestro de herrería; don Juan Carlos Sánchez, capitán de artillería retirado, sastre; don José Luis Sánchez, capitán de artillería de pardos, carpintero; don José Domingo Bracho, soldado de milicias y don José García y Oliva, abogado de los Reales Consejos y Real Audiencia.

Dentro de la red de relaciones que legitiman la actuación del gobernador Primo de Rivera, las respuestas de los testigos permiten adentrarnos en la complejidad del entramado social de los vínculos que sustentan las relaciones de poder entre individuos y colectivos, en correspondencia con los códigos simbólicos que definen comportamientos, actitudes, costumbres y prácticas. En estas dependencias recíprocas, lo esencial era el individuo en su imbricación social, pues en su contacto con los otros, se dependía tanto de rivales y contrarios, como de amigos y aliados en una relación que no siempre era armónica. En este contexto socio-simbólico, en

23 AHNM, Consejos, 20481, f. 62. 
su mayoría, las respuestas de los testigos coincidieron en la "buena actuación" del gobernador. Especial mención se hizo al interés puesto en el aprovechamiento y defensa de los recursos colectivos, a la observancia de la moral y buenas costumbres y en su disposición al fiel cumplimiento de la legislación. Por ello su gestión se valora como positiva. Ello lo demuestra el veredicto del juez residenciador.

"En cuanto a la pesquisa secreta, sobre la imparcialidad, rectitud y celo en el desempeño de sus respectivos encargos, castigando los pecados públicos, exterminando y celando el contrabando conforme a Reales disposiciones, manteniendo en paz y justicia a los vecinos, dedicándose con la mayor eficacia a todo lo concerniente al bien público y con especialidad al fomento de las sementeras de algodón con un comercio floreciente, asistiendo personalmente a la casa de los herreros y carpinteros para dirigirlos en el modo y forma de su trabajo, lo que ha resultado en beneficio para la gente pobre y en particular a toda la provincia... Debo declararlo 'bueno, celoso e íntegro Ministro', y acreedor a que la piedad de S.M. atienda sus méritos y buenos servicios y le conceda los empleos que sean de su Real agrado". ${ }^{24}$

Las respuestas al interrogatorio y el veredicto del juez residenciador sólo responden a la mentalidad de la época pues, los vínculos que sustentan las relaciones de poder entre individuos y colectivos se corresponden con los códigos que revelan actitudes y comportamientos, expresados en la fidelidad y la lealtad.

En referencia a la residencia pública en la cual el juez residenciador recibió las quejas, denuncias y reclamos de vecinos que se sentían agraviados por algunas medidas tomadas por el gobernador, se decidió imponerle de cinco cargos definitorios, una vez otorgado el tiempo correspondiente para que alegara lo que considerase conveniente. La "sentencia definitoria" manifiesta esos cargos y las sanciones impuestas en cada caso.

Una relación de los vecinos que desempeñaron funciones de gobierno durante el mandato de Primo de Rivera, revela los modos y maneras que adquirió el funcionamiento del poder a escala local y provincial. De algún modo, vecinos y /o funcionarios de gobierno compartían unas prácticas que generaban redes de relaciones de amplio alcance y conexiones en diversos ámbitos de poder. En tal sentido, el complejo mundo de las relaciones provinciales se sustenta en las propias relaciones vecinales.

En el entorno del gobernador estaban sujetos dedicados indistintamente a los negocios y a la política. Entre ellos destacó el capitán de mili-

24 AGN, Caracas, Causas de Residencia, T. LXXII, f. 224vto. 
cias don Ignacio Baralt, quien actuó como fiador cuando el gobernador se juramentó en el cargo, Justo Menacho, Francisco de Larrumbide, Tomás de Quintana, Sebastián de Esponda y Antonio de Cabrera e Inciarte. Otros como Francisco de Larrumbide, José Díaz Varela y Tomás de Quintana, fueron testigos de la residencia secreta que se le tomó a dicho gobernador. Buena parte de estos vecinos desempeñaron cargos en el Cabildo como alcalde, regidor y procurador general.

En el caso de Ignacio Armada, quien gobernó la provincia entre 1794 y 1799, los Cabildos eclesiástico y secular de Maracaibo, Mérida, San Cristóbal, la villa de Perijá y la Grita de la provincia de Maracaibo, solicitaron en 1797 la dispensa de su residencia cuando aún le quedaban dos años de gobierno. Alegaron la "excelente conducta en el desempeño del cargo". Como prueba anexaron las cuatro representaciones de estos Cabildos, en las cuales solicitaron fuera prorrogada su gestión por cinco años. En una de ellas expusieron que ".. ha ejecutado obras en beneficio del vecindario, el desinterés, arreglados procedimientos y celo religioso con que se ha dedicado a extinguir los pecados públicos, al bien de todos los pobres y ha conseguido la reedificación de la iglesia parroquial, única en dicha ciudad....". ${ }^{25}$

A esta solicitud se agregó la del propio gobernador Armada y de su apoderada y hermana María Teresa de Armada, quienes aludieron que con motivo del fallecimiento de su hermano el marqués de Santa Cruz de Rivadulla en la ciudad de Santiago, Reino de Galicia, debía trasladarse a esta localidad para hacerse cargo del marquesado y sus estados, en su condición de legítimo heredero del mayorazgo familiar. ${ }^{26}$

En julio de 1798 el rey le concedió el pedimento de separarse del cargo de gobernador a fin de que pudiera regresar a España. En octubre del mismo año, por real cédula fechada en San Lorenzo le fue dispensada la residencia secreta y se declaró lo que debía ejecutarse en cuanto a la pública. ${ }^{27}$ Esta dispensa se explica, en el marco de la relación poder local-poder monárquico, en la lucha por el poder entre gobernantes-gobernados y en la cual privaba el interés colectivo, pues la Monarquía era la cúspide del Estado y el Reino constituía la base del mismo. Ninguno suponía la sumisión del otro. De ahí, las fidelidades y lealtades mutuas.

25 Archivo General de Simancas (en adelante AGS), Gobierno de Maracaibo, Secretaría de Guerra. Exp. 6, ff. 324-331.

26 Ibídem, f. 325.

27 AGN, Caracas, Causas de Residencia, T. XLVI, ff. 230-231. 
Entre 1796 y 1797, se produjeron otras manifestaciones de descontento en relación con el ordenamiento de las residencias. En 1796 el Cabildo de Maracaibo envió una representación al virrey en la que se solicitó su extinción, pues “... el infeliz estado de pobreza en que se halla la provincia, hace que no sufra los crecidos gastos que ocasionan las residencias....". ${ }^{28}$ Lo conveniente sería, según la representación, que el gobernador fijara edictos convocatorios para que todo aquel que se sintiese agraviado lo hiciera saber en un lapso de sesenta días, luego la denuncia seguiría su curso normal. Esto no traería más gastos que los procesales.

En 1797 el Cabildo maracaibero señalaba “... el deplorable y exhausto estado en que se mira vuestra miserable ciudad y provincia espera que se le exonere a sus gobernadores y ministros del grave juicio de residencia.... de este mal que tanto recelo ha traído. Sus fieles, leales y amantes vasallos esperamos se digne mirarnos con ojos de piedad....". ${ }^{29}$ Según la representación, la solución estaría en manos de la Real Audiencia de Caracas, pues podía poner remedio a las irregularidades presentadas.

Las opiniones coincidieron en señalar que la residencia, lejos de ser favorable a la provincia, le era perjudicial y sumamente gravosa. Al parecer, razones inherentes a la autonomía local se unen a otras de carácter monetarista y fiscal como el costo económico que suponía dicho procedimiento. Razones más que suficientes para solicitar la dispensa de las residencias.

Esto debe enmarcarse en el contexto de las redes de relaciones e interdependencias recíprocas que sustentaban el ejercicio del poder. La comunidad local representada en el Cabildo y la máxima autoridad provincial, se identificaban en situaciones en las que sus intereses colectivos se veían afectados. De ahí, las muestras de afecto, reconocimiento, solidaridad y lealtad. Acciones de este tipo, fortalecían y aumentaban las redes de sociabilidad que garantizaban poder e influencia.

En 1804, en el marco de lealtades que unían y separaban a los miembros del Cabildo maracaibero, en el cual quedaban expresados los intereses de los grupos de poder local, el gobernador Miyares recibió apoyo de sus autoridades y otros funcionarios para solicitar al virrey gestionar la dispensa del juicio de residencia, como gracia en beneficio público. El gobernador Miyares, apoyándose en la prerrogativa que tenían algunos funciona-

28 AGI, Caracas, 27.

29 Ibídem. 
rios, por ser caballero de la Orden de Carlos III y como fiel y leal servidor del rey, se sentía con derecho para solicitar esta exención, para lo cual recibió el apoyo de los miembros del Cabildo.

En agosto de ese año, remitió a las autoridades correspondientes la "Representación y testimonio del acta del acuerdo del cabildo, justicia y regimiento de Maracaibo", mediante la cual se adujeron las razones para solicitar la dispensa de la residencia, sin perjuicio de los que se sintieran agraviados de sus providencias o de los demás ministros. La representación observaba que por ser el gobernador Miyares uno de los más fieles y celosos ministros de su majestad, cuyo gobierno había mostrado gran prudencia y rectitud, era merecedor de tal beneficio y junto a él los demás funcionarios que le habían acompañado en su gestión. Esta dispensa, según el Ayuntamiento maracaibero, contribuiría a su "Real benignidad" y al beneficio de toda la provincia. ${ }^{30}$

Entre los capitulares que gestionaron tal solicitud, figuraban Andrés María de Manzanos, Zenón de Veira, Juan Hernández Caballero y Diego de Melo, hombres de reconocida solvencia pública, dedicados a la política y a los negocios. Entre otras razones, argumentaron a su favor su celo y fidelidad como ministro de su majestad, su prudencia y rectitud, la apertura de nuevos caminos, lo cual representaba una ventaja para el comercio, la administración de justicia, las disposiciones para la defensa de la provincia y el celo oportuno en los intereses de la Real Hacienda. En definitiva, como fiel representante de la Corona, era merecedor de tal beneficio. "Por todo lo cual y principalmente por la notoriedad de la recta, fiel conducta de nuestro actual gobernador en todos los asuntos de su incumbencia = este ayuntamiento suplica a V.M.... se sirva dispensar la residencia..., gracia que espera alcanzar en beneficio público". ${ }^{31}$

La residencia ordenada al gobernador Miyares creó cierto malestar e inconformidad en la provincia. En tal sentido, el Cabildo en sesión conjunta acordó levantar un acta para manifestar ante el rey su descontento. Expresaron que no había motivos para que a un "... funcionario de la notoriedad del gobernador Miyares se le intente someter a tal procedimiento, y menos aún a nuestra ciudad donde se tiene la experiencia de los perjuicios irreparables y de las ruinas causadas por las residencias...". 32

30 Archivo de la Academia Nacional de la Historia, (Caracas), Papeles de Miyares, T. II, ff. 124-136.

31 AGI, Caracas, 382.

32 Ibídem. 
Esta representación del Cabildo fue elocuente al señalar:

- "Está persuadido señor este Ayuntamiento que los fines que se propusieron para el establecimiento de las residencias, fue sanos y justos y que era sin duda un recurso necesario para freno del despotismo de algunos malos ministros de justicia, los cuales a pretexto de la distancia y de su independencia gobernaban a su antojo.

- De nada más sirve una Residencia que de imponer una extorsión destructora a muchos de nuestros fieles vasallos que han desempeñado fielmente sus obligaciones en los cargos públicos, pues sin duda que de todos, cuando no hay culpados, como sucede por lo regular, deben salir los grandes y crecidos costos de la comisión.

- La presencia de los malintencionados que nunca faltan en los pueblos, los cuales a la sombra de una secreta pesquisa, vomitan las más horrorosas calumnias e intrigas con que logran a lo menos por efecto de sus perversas ideas, ver sembrada la discordia entre los vecinos, encendido el odio y rencor de que nacen las malas voluntades e innumerables pleitos con que se acaban y arruinan".

La representación revela que esta práctica no parece contar con el beneplácito y apoyo del gobierno local, pues supone cierta sumisión al poder real y en cierto modo una carga económica más, al tener que sufragar los salarios de quienes la ejecutan. Para los objetivos propuestos en la investigación, es fundamental precisar los resultados de las diligencias practicadas en la solicitud de exención de la residencia al gobernador Miyares. Hasta ahora, no ha sido posible localizar la documentación que permita conocer si la residencia se realizó o no.

\section{Consideraciones finales}

Se aportan elementos teóricos-metodológicos para analizar y comprender las relaciones de poder alrededor del ejercicio del gobierno provincial de Maracaibo durante las últimas décadas borbónicas y primeros años del siglo XIX. Los resultados aquí expuestos sólo abren el camino para la reconstrucción de un proceso histórico que redescubre las prácticas políticas de los grupos dominantes en las instancias de poder local y provincial.

En la relación soberano-súbdito, los valores sociales tradicionales de fidelidad, lealtad y solidaridad, involucran indistintamente a la vida social y política, pues el entramado de dependencias e interdependencias no establece diferencias en la distribución y uso del poder. En este marco de rela- 
ciones sociales, el análisis de los juicios de residencia permite penetrar en la complejidad del funcionamiento y socialización del poder en el terreno de un hacer, un deber y un quehacer, en el cual las representaciones y prácticas colectivas expresan la relación dialéctica entre gobernantes y gobernados. Los juicios a los que son sometidos los funcionarios provinciales, además de una práctica legal y usual, representan el poder que sus agentes sociales significan y construyen.

Las residencias ordenadas a los gobernadores de la provincia de Maracaibo en el período aquí considerado, revelan cómo colectivamente se participa de unas prácticas que impregnan la cotidianidad local y explican las relaciones e interdependencias establecidas en torno a privilegios y prerrogativas que distinguen a las comunidades locales. De este modo, lo ocurrido con las pesquisas públicas y secretas dispuestas, son características del entramado social alrededor del ejercicio del gobierno provincial.

El descontento que esta práctica generó entre miembros prominentes de la sociedad maracaibera y su órgano de gobierno local, pone de manifiesto la reacción de los agentes sociales que controlaban el poder local en el marco de una nueva dinámica social y política. Esto explica que hacendados, comerciantes, eclesiásticos y funcionarios de gobierno político y militar conjugaran lealtades, solidaridades e intereses, reforzando lazos de amistad, negocios y clientelas. En este sentido, acciones a favor de los gobernadores son reveladoras de las redes de relaciones del poder, pues en la mayoría de los casos el veredicto certifica los "méritos y buena gestión" del funcionario residenciado. 



\section{Apéndice}

\section{Interrogatorio secreto incluido en el juicio de residencia del gobernador Joaquín Primo de Rivera (1794)}

1. Si conocen al brigadier Joaquín Primo de Rivera, gobernador e Intendente que es de esta Provincia, a su teniente don Juan Esteban de Valderrama, a los alcaldes ordinarios y demás ministros; si son parientes, amigos o enemigos y si les comprende alguna otra circunstancia de las generales de la ley, digan y den razón.

2. Si saben que dicho señor gobernador, su teniente y demás jueces y ministros administran cumplidamente justicia a las partes o dejaron de administrarla por amor, temor, odio, enemistad, dádivas, ruegos o parcialidades que hubieren tenido con personas poderosas, expresen en qué causas, o casos, qué daños y perjuicios causaron y a quiénes.

3. Si saben que los referidos han dado buen ejemplo, o causado escándalo en el modo de vivir o portarse, y sin han dejado de castigar los pecados públicos y escandalosos como concubinatos, usuras, juegos prohibitivos, juramentos, blasfemias, alcahuetes o encubridores de malos hechos, y a los vagabundos, ociosos y mal entretenidos, disimulándoles sus hechos, sin aplicarles las penas establecidas en derecho, o si han dejado de ejecutarlo por interés u otros fines particulares.

4. Si saben que han cuidado de la buena educación de la juventud, procurando que sus padres o parientes aplicasen a los jóvenes algún ejercicio útil a la República, sin permitirles la ociosidad, que es el origen de todos los vicios, proporcionándoles maltratos y destinando a cada uno a aquel oficio que más le llamaba la inclinación conforme a su estado y condición.

5. Si saben que el expresado Sr. gobernador e intendente ha velado sobre la conducta y procedimientos de sus tenientes y comisionados, procurando que cada uno cumpliere con puntualidad y exactitud en sus respectivos encargos, sin permitirles que causasen extorsiones, robos e injusticias a los vecinos, o si la han disimulado con agravio de las quejas y perjuicios de los demás vasallos.

6. Si saben que dicho Sr. gobernador, sus tenientes, alcaldes ordinarios y demás que han ejercido jurisdicción en esta Provincia, han determinado, castigado o condenado alguno en grave pena, sin consulta primero con la Real Audiencia del Distrito como está mandado y sin oírles sus descargos, ni su legítimamente convenidos, especifiquen los casos y personas. 
7. Si han permitido, auxiliado o disimulado algún alboroto popular, sedición o motín que conspirare contra la autoridad Real o de sus ministros y si por no dar las correspondientes providencias se siguieron muertes, escándalos $\mathrm{u}$ otros excesos.

8. Si saben que hubiesen dejado de obedecer y dar cumplimiento a las cédulas, provisiones y otros mandatos del Rey Nuestro Señor, de su Real y Supremo Consejo de estos dominios o de la Real Audiencia del Distrito, o si del mismo modo dejaron de observar las leyes, particularmente las hechas en Toledo, especificando las Reales Ordenes, leyes o disposiciones que dejaron de observar y los perjuicios que resultaron.

9. Si saben que dejaron de dar audiencia a los que a su tribunal acudían a pedir justicia, si les trataron mal, acusándoles o injuriándoles de palabra su obra especialmente a los pobres, especifiquen las personas a quiénes.

10. Si saben que en el despacho de las causas y negocios fueron omisos o, diligentes molestando a las partes con injustas dilaciones o si consintieron semejantes desmanes.

11. Si saben que en sus autos y sentencias hubiesen llevado dichos excesivos, contraviniendo a la tasa del arancel, o si consintieron que sus oficiales u otros ministros lo llevaran, expresen lo que hubieren dicho, y en qué causas y si los llevaron a las Indias, pobres u otras miserables personas.

12. Si cuidaron que tuviese puesta desde el principio de su gobierno en las Audiencias públicas, una copia en tabla del Real Arancel, para que constasen los legítimos derechos que debían llevar ellos como los demás ministros de sus respectivos tribunales.

13. Si saben que en las multas que impusieron en los pleitos y causas aplicaron la parte correspondiente a la Real Cámara y si cuidaron de tener libros en que sentarlas y si omitieron entregarla en la Real Contaduría a los respectivos receptores.

14. Si saben que dicho señor gobernador y demás jueces ordinarios hubiesen sido omisos en defender y conservar la jurisdicción, las regalías del Patronato Real y demás preeminencias Reales, dejándolos usurpar o inhibiéndose de los negocios en que se trataba de ellos, por temor de censuras, interés u otros fines particulares.

15. Si saben que hubieren permitido u otra dentro de la provincia, se erigiere, fundare o construyese alguna iglesia, parroquia, monasterio, hospital u otro lugar sin licencia de S.M. en contravención de las leyes y disposiciones reales.

16. Si saben que han impuesto alguna sisa derrama o contribuyan sin licencia de sello por alguna obra pública o por otro efecto, expresen la cantidad, para qué fines, sobre qué cosas fueron impuestas, si se observaron sobre el asunto, y si invirtieron en los fines de sus destinos u otros distritos. 
17. Si cuidaron que hubiese cárcel con la seguridad correspondiente y con las prisiones necesarias y si por no haberla en esta conformidad, hicieron fuga algunos delincuentes, especificando los que fueron.

18. Si cuidaron que los alcaldes de dicha Real cárcel tuvieran libro en que sentar las entradas y salidas de los presos y de que estuviesen con separación los hombres de las mujeres y si hacían las visitas de cárcel correspondiente.

19. Si atendieron el abasto público y cuidaron de que las carnicerías estuvieren provistas, y también los lugares públicos en que acostumbran vender los demás mantenimientos y que todo fuese por su justo precio, o que si por descuido se vendieron por más de lo regular.

20. Si cuidaron de la limpieza de las calles y que estas se mantuvieran empedradas y desocupadas y así mismo de que los edificios públicos se compusieran y repararan con el menor costo posible.

21. Si han cuidado con particular atención de que los caminos públicos estén compuestos, desmontados y limpios para que los caminantes puedan transitar libremente, y si por su defecto se han seguido desgracias, perjuicios, expresen a quiénes, cuándo y en qué casos.

22. Si cuidaron que hubiere ordenanzas en esta ciudad para su mejor régimen y si los hay cuidaron de su puntual y debida observancia.

23. Si procuraron que se dieren y tomaron las cuentas, los bienes, rentas y propios de la ciudad y de caudales, depósitos y si permitieron se pasare alguna partida indebida y no hicieron pagar los alcances.

24. Si saben que alguno de los susodichos hubiese rematado tales caudales, propios o rentas, en todo o en partes o hubieren sido fiadores o abonadores de los rematadores o permitido que lo fuesen los de su familia o dependientes.

25. Si permitieron gastar los propios o rentas referidas en fines ajenos, sin destino y en casos que no condujeren al bien común de la República.

26. Si saben que los jueces cometieron el examen de testigos en causas criminales o civiles arduas a los escribanos u otras personas sin justa causa, omitiendo hacerlo por sus propias personas o sin actuar ante otros escribanos que no fueren públicos del número habiéndolos en esta ciudad.

27. Si han descuidado o tolerado que dichos escribanos no anotasen en los tales procesos los derechos que en ellos se le tasaron, o si fueron negligentes en hacerlo ejecutar.

28. Si saben que dicho Sr. gobernador o su teniente asesor por si o por interpuestas personas trataron o contrataron, atravesando y comprando mercaderías de ropas, frutos de la tierra u otras cosas para revenderlas a subidos precios, impidiendo que otros los comprasen y vendiesen, y si los embarcaban fuera de la ciudad para sus ventas, o teniendo estancias, huertas, tierras, sementeras y cosas propias o si lo han ejecutado por sus mujeres e hijos que no fuesen casados y velados que viviesen aparte. 
29. Si saben que por sus personas u otras interpuestas, hijos, criados y dependientes recibieron algunos regalos, dádivas o cohechos, u otros, si por dejar de hacer recibieron algunos intereses o si igualmente los llevaron por la provisión de las tenencias, corregimientos u otros empleos y oficios, especificando las causas en que intervinieron semejantes cohechos, los perjuicios que se hayan seguido, y los sujetos de quienes recibieron iguales regalos e intereses.

30. Si saben que dicho Sr. gobernador y demás ministros hicieron violencia a mujeres casadas, viudas o solteras en sus casas, si alguno de ellos estuvo públicamente amancebado o con escándalo, o si cometió algún otro delito de esta naturaleza.

31. Si alguno de los susodichos fue abogado, procurador o solicitador de causas ajenas, así en sus tribunales como en otros de la gobernación llevando por ello algunos intereses o si fueren árbitros de compromisos.

32. Si saben que dicho Sr. gobernador ha hecho visita general en toda la provincia, si lo hizo más de una vez y con qué causa.

33. Si cuidaron del buen tratamiento de los indios, haciéndoles justicia, manteniéndolos en paz, sin gravarlos con tributos de los que están dispuestos por reales ordenes, si consintieron que los injiriesen, si se sirvieron de algunos de ellos sin pagarles su trabajo, si cuidaron de que los caciques no los maltratasen, instruyendo para ello a los corregidores conforme a las leyes recopiladas para estos dominios, si se sirvieron de los incorporados a la Real Corona y consintieron ejecutar alguna de estas cosas y no procuraron la conversión y reducción de dichos indios.

34. Si despacharon con prontitud sus causas, o las detuvieron mucho tiempo en las cárceles, si conforme a las ordenanzas municipales fueron alimentados en ellos pasándoles diariamente lo necesario, o si por su descuido han producido hambres o necesidades o por falta de alimentos han muerto en prisión.

35. Si dicho Sr. gobernador ha puesto el correspondiente celo y vigilancia a fin de establecer en los pueblos de indios escuelas de primeras letras para la enseñanza de la lengua castellana como está mandado por su Majestad.

36. Si saben que hubiese sido negligente en providencias que los corregidores en sus respectivos pueblos, cuiden de que hubiese casa de cabildo, que los indios hicieren sus labranzas y tuviesen caja de comunidad, y si no distribuyeron los fondos de dicha caja en los objetos a que hayan destinados por las leyes o si se aprovecharon de ellos.

37. Si en las elecciones de oficios concejiles y demás acuerdos de cabildo, dejaron votar libremente a los regidores o si por el contrario los obligaron con violencia a persuasiones a que votaran en personas de su parcialidad.

38. Si han cumplido con visitar las cárceles en los días prevenidos por ley, viendo y examinando los presos, por que han sido detenidos en ella los delincuentes. 
39. Si dicho Sr. gobernador como Intendente que también ha sido de esta provincia ha cumplido guardando lo dispuesto en la Real Ordenanza e instrucción de Intendentes de Nueva España.

40. Si saben que ha decomisado los géneros y efecto de contrabando o los ha tolerado contra las reales disposiciones, o teniendo parte en ellos, o si los han ocultado o desmembrado, o permitido su ocultación, o desmembración y si en los parajes pertenecientes a la costa han permitido el arribo de las embarcaciones extranjeras para hacer trato ilícito y sacar los frutos de la tierra. $\mathrm{Si}$ se han interesado en ello o llevado interés por la tolerancia y disimulo, y si las embarcaciones que han entrado a dichos puertos con las legítimas licencias han sido registradas con la exactitud necesaria, o si al contrario, siendo omitida esta formalidad se les han dado certificación del cumplimiento de sus registros o destinos.

41. Si dicho Sr. gobernador durante su gobierno ha hecho alguna cosa memorable en esta Provincia al servicio de ambas majestades y de la causa pública, exprésenla con toda individualidad. 